INFNCA-TH0303

\title{
Antineutrinos from Earth: A reference model and its uncertainties
}

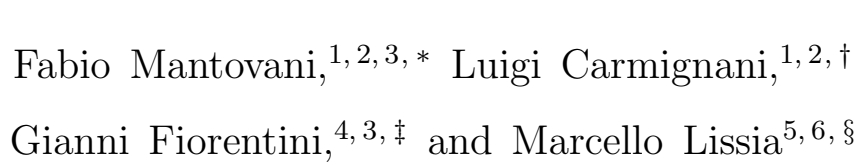 \\ ${ }^{1}$ Dipartimento di Scienze della Terra, \\ Università di Siena, I-53100 Siena, Italy \\ ${ }^{2}$ Centro di GeoTecnologie CGT,I-52027 San Giovanni Valdarno, Italy \\ ${ }^{3}$ Istituto Nazionale di Fisica Nucleare, \\ Sezione di Ferrara, I-44100 Ferrara, Italy \\ ${ }_{4}^{4}$ Dipartimento di Fisica, Università di Ferrara, I-44100 Ferrara, Italy \\ ${ }^{5}$ Istituto Nazionale di Fisica Nucleare, \\ Sezione di Cagliari, I-09042 Monserrato (CA), Italy \\ ${ }^{6}$ Dipartimento di Fisica, Università di Cagliari, I-09042 Monserrato (CA), Italy
}

(Dated: August 31, 2003; revised November 25, 2003)

\begin{abstract}
We predict geoneutrino fluxes in a reference model based on a detailed description of Earth's crust and mantle and using the best available information on the abundances of uranium, thorium, and potassium inside Earth's layers. We estimate the uncertainties of fluxes corresponding to the uncertainties of the element abundances. In addition to distance integrated fluxes, we also provide the differential fluxes as a function of distance from several sites of experimental interest. Event yields at several locations are estimated and their dependence on the neutrino oscillation parameters is discussed. At Kamioka we predict $N(\mathrm{U}+\mathrm{Th})=35 \pm 6$ events for $10^{32}$ proton yr and $100 \%$ efficiency assuming $\sin ^{2}(2 \theta)=0.863$ and $\delta m^{2}=7.3 \times 10^{-5} \mathrm{eV}^{2}$. The maximal prediction is 55 events, obtained in a model with fully radiogenic production of the terrestrial heat flow.

PACS numbers: 91.35.-x, 13.15.+g, 14.60.Pq, 23.40.Bw
\end{abstract}

*Electronic address: mantovani@fe.infn.it

${ }^{\dagger}$ Electronic address: luigi.carmignani@unisi.it

${ }^{\ddagger}$ Electronic address: fiorenti@fe.infn.it

$\S$ Electronic address: marcello.lissia@ca.infn.it 


\section{INTRODUCTION}

By looking at antineutrinos from reactors, KamLAND [1] has confirmed the oscillation phenomenon previously discovered by SNO [2] with solar neutrinos and has provided crucial information on the oscillation parameters. Putting together the results of solar and terrestrial experiments, the best fit is obtained at $\delta m^{2}=7.3 \times 10^{-5} \mathrm{eV}^{2}$ and $\sin ^{2}(2 \theta)=0.863[\underline{3}]$. Since we know their fate from production to detection, neutrinos can now be used as physical probes.

Furthermore, the detector is so pure and the sensitivity is so high that KamLAND will be capable of studying geoenutrinos, the antineutrinos originating from Earth's natural radioactivity. Indeed, from a fit to the experimental data the KamLAND Collaboration reported four events associated with ${ }^{238} \mathrm{U}$ and five with ${ }^{232} \mathrm{Th}$ decay chains. This result, obtained from an exposure of just 162 ton yr, provides the first insight into the radiogenic component of the terrestrial heat. KamLAND has thus opened a new window for studying Earth's interior and one expects more precise results in the near future from KamLAND and other detectors which are presently in preparation.

The argument of geoneutrinos was introduced by Eder [4] in the 1960's and it was extensively reviewed by Krauss et al. [5] in the 1980's. Raghavan et al. [6] and Rothschild et al. 7] ${ }^{1}$ remarked on the potential of KamLAND and Borexino for geoneutrino observations. Fiorentini et al. [8, 9, 10] discussed the relevance of geoneutrinos for determining the radiogenic contribution to Earth's heat flow and their potential for improving our knowledge of oscillation parameters, see also Ref. [11].

In preparation to the data which will become available in the near future, we present a systematic discussion of geoneutrinos, which incorporates the best geological and geochemical information on their sources and outlines the main uncertainties, so as to understand what can be gained from the study of geoneutrinos concerning both Earth's interior and neutrino properties. With this spirit, we shall consider the following points.

(i) We provide a reference model that incorporates the best available knowledge for the distribution of U, Th, and K in Earth's interior.

(ii) Within this model we predict neutrino fluxes and signals for detectors at different

\footnotetext{
${ }^{1}$ We shall always refer to the version available as arXiv:nucl-ex/9710001
} 
positions on Earth.

(iii) We estimate uncertainties of neutrino fluxes and signals corresponding to uncertainties of the $\mathrm{U}$, Th, and $\mathrm{K}$ distributions.

\section{THE REFERENCE MODEL: ELEMENT DISTRIBUTIONS AND GEONEU- TRINO FLUXES}

A global look at Earth's interior is useful before entering a detailed discussion on the element distributions. The amount of information which we (assume to) have on Earth's interior is somehow surprising, if one considers that the deepest hole which has ever been dug is probably only ten kilometers deep, a mere dent in planetary terms.

The outer layer is the relatively thin crust, divided in two types, continental crust (CC) and oceanic crust (OC). The former averages $38 \mathrm{~km}$ in thickness, varying around the globe from 20 to $70 \mathrm{~km}$, and it is made primarily of light elements such as potassium, sodium, silicon, calcium, and aluminium silicates. The oceanic crust is much thinner, from about 6 to $8 \mathrm{~km}$.

Inside this crustal skin is Earth's mantle which is $2900 \mathrm{~km}$ deep overall. Largely made up of iron and magnesium silicates, the mantle as a whole accounts for about $68 \%$ of Earth's mass. One distingushes the upper mantle ${ }^{2}$ (UM) from the lower mantle (LM), however, the seismical discontinuities between the two parts do not necessarily divide the mantle into layers. The main questions about the mantle are does it move as a single layer or as multiple layers? Is it homogeneous in composition or heterogeneous? How does it convect? These questions sound simple, but the answers are complex, possibly leading to more questions, see Ref. [12].

Inside the mantle is Earth's core, which accounts for about 32\% of Earth's mass. Based on comparison with the behavior of iron at high pressures and temperatures in laboratory experiments, on the seismic properties of the core, and on the fact that iron is the only sufficiently abundant heavy element in the universe, the core is generally believed to be made primarily of iron with small amounts of nickel and other elements. Over thirty years ago, however, it was suggested that a significant amount of potassium could be hidden in

\footnotetext{
${ }^{2}$ We shall define the upper mantle as the shallow mantle plus the transition region, i.e., the region below the crust down to $677 \mathrm{~km}[15]$.
} 
Earth's core, thus providing a large fraction of the terrestrial heat flow through ${ }^{40} \mathrm{~K}$ decay. This controversial possibility has been revived recently in Ref. [13].

Uranium, thorium, and potassium are lithophile elements, which accumulate in the continental crust. Their abundance in the mantle is much smaller, however, the total amounts are comparable with those in the crust, due to the much larger mantle mass. The core is generally believed to contain negligible amounts of these elements.

A global description of the present crust-plus-mantle system is provided by the bulk silicate earth (BSE) model, a reconstruction of the primordial mantle of Earth, subsequent to the core separation and prior to crust differentiation, based on geochemical arguments. In the BSE model the uranium abundance ${ }^{3}$ is $a_{\mathrm{BSE}}(\mathrm{U})=2 \times 10^{-8}$, and one has $\mathrm{Th} / \mathrm{U}$ $\equiv a(\mathrm{Th}) / a(\mathrm{U})=3.9$ and $\mathrm{K} / \mathrm{U} \equiv a(\mathrm{~K}) / a(\mathrm{U})=1.14 \times 10^{4}$, where the quoted values are averages between different estimates, all consistent with each other to the level of $10 \%$ or better, see Table In the BSE model the total masses of uranium, thorium and potassium are thus $M(\mathrm{U})=0.81 \times 10^{17} \mathrm{~kg}, M(\mathrm{Th})=3.16 \times 10^{17} \mathrm{~kg}$, and $M(\mathrm{~K})=0.49 \times 10^{21} \mathrm{~kg}$.

The equation relating masses and heat production is

$$
H=9.5 M(\mathrm{U})+2.7 M(\mathrm{Th})+3.6 M(\mathrm{~K}),
$$

where $H$ is in TW, $M(\mathrm{U})$ and $M(\mathrm{Th})$ are in units of $10^{17} \mathrm{~kg}$, and $M(\mathrm{~K})$ in units of $10^{21} \mathrm{~kg}$.

In the BSE model, the contributed heat production rates are $H(\mathrm{U})=7.6 \mathrm{TW}, H(\mathrm{Th})=$ 8.5 TW, and $H(\mathrm{~K})=1.8 \mathrm{TW}$, for a total of about one half of the observed terrestrial heat flow $\left(H_{E} \approx 40 \mathrm{TW}\right)$.

\section{A. Uranium, thorium, and potassium distributions}

Our aim is to build a reference model (labeled as "ref"), which incorporates the best available knowledge of U, Th and K distributions inside Earth. Concerning Earth's crust, we distinguish oceans and seawater, the continental crust, subdivided into three sublayers (upper, middle, and lower), sediments and oceanic crust. All these layers have been mapped in Ref. [14], which provides values of density and depth over the globe on a grid with $2^{\circ}$ steps. We distinguish next the upper mantle (extending down to about $600 \mathrm{~km}$ ), the lower mantle

\footnotetext{
${ }^{3}$ We shall always refer to element abundances in mass and we remind the reader that the natural isotopic composition is ${ }^{238} \mathrm{U} / \mathrm{U}=0.993,{ }^{232} \mathrm{Th} / \mathrm{Th}=1$ and ${ }^{40} \mathrm{~K} / \mathrm{K}=1.2 \times 10^{-4}$.
} 
(down to about $2900 \mathrm{~km}$ ), and the core, and use the preliminary reference earth model (PREM) [15] for the values of the density at each depth, assuming spherical symmetry.

For each component, one has to adopt a value for the abundances $a(\mathrm{U}), a(\mathrm{Th})$, and $a(\mathrm{~K})$. In the literature of the last twenty years one can find many estimates of abundances for the various components of the crust (OC, upper CC, lower CC, ..), generally without an error value (see Tables [I], [II] and [V]), two classical reviews being in Refs. [16, 17] and a most useful source being provided by the GERM Reservoir database 18].

For the upper mantle we are aware of several estimates by Jochum et al. 19], White [20], O'Nions and McKenzie [21], Hofmann [22], and Zartman and Haines [23]. In this respect data obtained from material emerged from unknown depths are assumed to be representative of the average composition down to about $600 \mathrm{~km}$.

For each (sub)layer of the crust and for the upper mantle, we adopt as reference value for the uranium abundance $a^{\mathrm{ref}}(\mathrm{U})$ the average of the values reported in Tables II, III, and IV. Concerning Th and $\mathrm{K}$, we observe that the abundance ratios with respect to uranium are much more consistent among different authors than the corresponding absolute abundances. We shall thus take the average of ratios and from these construct the reference abundances for thorium and potassium:

$$
a^{\mathrm{ref}}(\mathrm{Th})=\langle\mathrm{Th} / \mathrm{U}\rangle a^{\mathrm{ref}}(\mathrm{U}) \quad \text { and } \quad a^{\mathrm{ref}}(\mathrm{K})=\langle\mathrm{K} / \mathrm{U}\rangle a^{\mathrm{ref}}(\mathrm{U})
$$

For the lower mantle, where no observational data are available, we resort to the BSE model, which — we recall — describes the present crust-plus-mantle system based on geochemical arguments.

The mass of each element $(X=\mathrm{U}, \mathrm{Th}, \mathrm{K})$ in the lower mantle $M_{\mathrm{LM}}(X)$ is thus obtained by subtracting from the BSE estimate the mass calculated for the crust and upper mantle:

$$
M_{\mathrm{LM}}(X)=M_{\mathrm{BSE}}(X)-M_{\mathrm{CC}}(X)-M_{\mathrm{OC}}(X)-M_{\mathrm{UM}}(X) .
$$

Reference abundances for the lower mantle are then obtained by dividing these values by its mass $M_{\mathrm{LM}}=2.9 \times 10^{24} \mathrm{~kg}$. According to geochemical arguments, negligible amounts of U, Th and $\mathrm{K}$ should be present in the core.

The resulting choice of input values for the reference model is collected in Tables 【II 【, and IV] Concerning this reference model, we remark the following points.

(i) The uranium mass in the crust $M_{c}(\mathrm{U})=0.35 \times 10^{17} \mathrm{~kg}$ is mainly concentrated in 
the continental part. The oceanic crust contributes as little as $0.005 \times 10^{17} \mathrm{~kg}$, since its impoverished by a factor of 20 and it is much thinner than the continental crust.

(ii) The estimated uranium mass in the upper mantle is about one sixth of that in the crust, whereas the lower mantle contains about as much uranium as the crust.

(iii) Note that in this refererence model, constructed so as to satifisy the BSE constraint (13), mantle depletion (with respect to BSE) extends to the lower mantle.

(iv) Similar considerations hold for thorium and potassium.

\section{B. The reference fluxes}

For each element $X$ the produced ${ }^{4}$ antineutrino fluxes at position $\vec{r}$ are defined as

$$
\Phi_{X}(\vec{r})=\frac{n_{X}}{4 \pi \mu_{X} \tau_{X}} \int_{V_{\oplus}} d \overrightarrow{r^{\prime}} \frac{\rho\left(\overrightarrow{r^{\prime}}\right) a_{X}\left(\overrightarrow{r^{\prime}}\right)}{\left|\vec{r}-\overrightarrow{r^{\prime}}\right|^{2}}
$$

where $\tau$ is the lifetime, $\mu$ is the atom mass, $n$ is the number of antineutrinos per decay chain, the integral is over the volume of the earth, $\rho$ is the local density, and $a_{X}$ is the abundance of the element $X$. We have evaluated the produced fluxes at several sites on the globe within the reference model $\left(a=a^{\text {ref }}\right)$. We concentrate here on a few locations of specific interest, see Tables $\nabla$. DI, and VII

(i) for the Kamioka mine, where the KamLAND detector is in operation, we predict an uranium flux $\Phi_{U}=3.7 \times 10^{6} \mathrm{~cm}^{-2} \mathrm{~s}^{-1}$, a comparable flux from thorium and a fourfold flux from potassium. Within the reference model, about $3 / 4$ of the flux is generated from material in the crust and the rest mainly from the lower mantle.

(ii) At Gran Sasso laboratory, where Borexino [24] is in preparation, we predict an uranium flux $\Phi_{\mathrm{U}}=4.2 \times 10^{6} \mathrm{~cm}^{-2} \mathrm{~s}^{-1}$, this larger flux arising from a bigger contribution of the surrounding continental crust. Thorium and potassium fluxes are correspondingly rescaled.

(iii) At the top of Himalaya, a place chosen so that the crust contribution is maximal, we find the maximum uranium flux $\Phi_{\mathrm{U}}=6.7 \times 10^{6} \mathrm{~cm}^{-2} \mathrm{~s}^{-1}$. The crust contribution exceeds $90 \%$.

(iv) On the Hawaii, a site which minimizes the crust contribution, we find $\Phi_{\mathrm{U}}=1.3 \times$ $10^{6} \mathrm{~cm}^{-2} \mathrm{~s}^{-1}$, originated mainly from the mantle.

\footnotetext{
4 The produced fluxes are calculated ignoring oscillations, which will be discussed later.
} 
These computed reference fluxes are generally larger than those of Rothschild [7], by a factor of order 30-50\%. This arises from several differences in the approaches.

(i) We have used a more recent and detailed map of Earth's crust: the grid is denser and several layers are distinguished.

(ii) We have a more detailed model for the mantle, correponding to the PREM density profile.

(iii) Most important, our reference values for the abundances in the continental crust are larger than that used in Ref. [7]. As an example, Rothschild et al. use for the continental crust $a_{\mathrm{CC}}(\mathrm{U})=0.91 \mathrm{ppm}$ from a classical review paper of 1985 [16]. Our reference model, when averaged over the different sublayers, yields $a_{\mathrm{CC}}(\mathrm{U})=1.5 \mathrm{ppm}$. This larger value arises from taking into account recent data, which are all higher than those quoted in Ref. [16].

The produced fluxes are computed ignoring the effect of oscillations, which depends on the distance $R$ between the detector and the source. For taking into account this effect, and also in view of understanding which portion of Earth can be accessed with a geoneutrino detector, it is useful to introduce quantities which contain more detailed information.

The differential fluxes $f(R)$ are obtained by grouping together all the sources which lie at the same distance $R$ from the detector

$$
f_{X}(R)=\frac{n_{X}}{4 \pi \mu_{X} \tau_{X}} \int_{V_{\oplus}} d \overrightarrow{r^{\prime}} \frac{\rho\left(\overrightarrow{r^{\prime}}\right) a_{X}\left(\overrightarrow{r^{\prime}}\right)}{\left|\vec{r}-\overrightarrow{r^{\prime}}\right|^{2}} \delta\left(R-\left|\vec{r}-\overrightarrow{r^{\prime}}\right|\right)
$$

Note that $f_{X}(R)$ actually depends also on the detector position $\vec{r}$ and just for semplicity of notation we drop this variable.

The cumulated fluxes $\phi(R)$ are defined as

$$
\phi_{X}(R)=\int_{0}^{R} d R^{\prime} f_{X}\left(R^{\prime}\right)
$$

They represent the cumulative effect of all sources within a distance $R$ from the detector: the total produced fluxes of Eq. (44) are clearly $\Phi_{X}=\phi_{X}\left(2 R_{\oplus}\right)$.

These quantities are plotted in Figs. 1 and 2 for the four sites (we only show the uranium contribution, the shapes of the other contributions being similar). We remark that we have been using an average density approximation, which presumably breaks down near the detector, where one should resort to a detailed geological study of the surroundings. From Fig. 2 one sees that in our model the region within $30 \mathrm{~km}$ from Kamioka or Gran Sasso originates about $15 \%$ of the total produced flux. Concerning the region where most of the 
flux is generated, one sees again from Fig. 2 that $50 \%$ of the produced flux originated within $400 \mathrm{~km}(800 \mathrm{~km})$ from Kamioka (Gran Sasso).

In Tables $\mathrm{VIII}\left[\mathrm{IX}\right.$ and $\mathrm{X}$ we present the numerical values of the contribution to $f_{X}(R)$ from the crust at Kamioka and Gran Sasso and that from the mantle (the assumed spherical symmetry of the mantle implies the same contribution at any site). These data will be useful for a detailed analysis of future experiments devoted to the study of geoneutrinos, in order to take into account the distance dependence of the survival probability.

\section{THE UNCERTAINTIES OF THE REFERENCE MODEL}

The fluxes of the reference model correspond to the best available knowledge about the crust and the interior of Earth, as derived from observational data and geochemical information on the global properties. An estimate of the uncertainties of the predicted fluxes is clearly useful.

Since the abundance ratios look relatively well determined, we concentrate on the uncertainties of the uranium abundances in the different layers and propagate them to the other elements. For the reference model, we have $M_{\mathrm{CC}}(\mathrm{U})=0.345 \times 10^{17} \mathrm{~kg}, M_{\mathrm{OC}}(\mathrm{U})=$ $0.005 \times 10^{17} \mathrm{~kg}$, the total mass of CC being $M_{\mathrm{CC}}=2.234 \times 10^{22} \mathrm{~kg}$. According to our model, the average uranium abundance in the $\mathrm{CC}$ is thus $a_{\mathrm{CC}}(\mathrm{U})=1.54 \times 10^{-6}$. We determine lower and upper limits by observing that the range of estimated uranium abundances is between $0.91 \times 10^{-6}[16]$ and $1.8 \times 10^{-6}[25]$

$$
\begin{aligned}
& \text { low: } a_{\mathrm{CC}}(\mathrm{U})=0.9 \times 10^{-6} ; a_{\mathrm{CC}}(\mathrm{Th})=3.7 \times 10^{-6} ; a_{\mathrm{CC}}(\mathrm{K})=0.94 \times 10^{-2} \\
& \text { high: } a_{\mathrm{CC}}(\mathrm{U})=1.8 \times 10^{-6} ; a_{\mathrm{CC}}(\mathrm{Th})=7.6 \times 10^{-6} ; a_{\mathrm{CC}}(\mathrm{K})=1.97 \times 10^{-2}
\end{aligned}
$$

We remark that there is an overall uncertainty of a factor 2 concerning the total amount of radioactive materials in the crust.

For the upper mantle, we take as extrema the two values known to us [19, 23] for uranium and we deduce thorium and potassium by rescaling

$$
\begin{aligned}
& \text { low: } a_{\mathrm{UM}}(\mathrm{U})=5 \times 10^{-9} ; a_{\mathrm{UM}}(\mathrm{Th})=13 \times 10^{-9} ; a_{\mathrm{UM}}(\mathrm{K})=6 \times 10^{-5} \\
& \text { high: } a_{\mathrm{UM}}(\mathrm{U})=8 \times 10^{-9} ; a_{\mathrm{UM}}(\mathrm{Th})=21 \times 10^{-9} ; a_{\mathrm{UM}}(\mathrm{K})=9.6 \times 10^{-5}
\end{aligned}
$$

Such a small uncertainty is perhaps optimistic, however, it is not influential for the future discussion in view of the relatively small amounts contained in the upper mantle. 
We remind the reader that no observational information is available for the lower mantle. For building a minimal model, we assume that the mantle is fully mixed and use for the whole mantle the lowest values estimated from samples coming from the upper mantle.

A maximal model can be obtained by assuming that the terrestrial heat is fully accounted by radiogenic production. This can be otained by keeping the BSE abundance ratios fixed and rescaling the total masses to $M(\mathrm{U})=1.67 \times 10^{17} \mathrm{~kg}, M(\mathrm{Th})=6.5 \times 10^{17} \mathrm{~kg}$, and $M(\mathrm{~K})=1.9 \times 10^{21} \mathrm{~kg} .{ }^{5}$ A natural implementation is obtained by choosing for the crust and upper mantle the highest observational estimates and placing the remaining mass in the lower mantle.

All this leads to

$$
\begin{aligned}
& \text { low: } \quad a_{\mathrm{LM}}(U)=5 \times 10^{-9} ; \quad a_{L M}(\mathrm{Th})=13 \times 10^{-9} ; a_{L M}(\mathrm{~K})=6 \times 10^{-5} \\
& \text { high: } \quad a_{L M}(\mathrm{U})=40 \times 10^{-9} ; a_{L M}(\mathrm{Th})=156 \times 10^{-9} ; a_{L M}(\mathrm{~K})=45.6 \times 10^{-5}
\end{aligned}
$$

The corresponding low and high estimates of the produced fluxes are also shown in Tables $\mathrm{V}$. VI, and VII for a few locations.

In view of assigning an uncertainty to the fluxes of the reference model one can take two different approaches.

(a) A conservative estimate: the error assigned to the reference value is half of the difference between the high and low estimates $\Delta \Phi_{\text {cons }}=\left(\Phi_{\text {high }}-\Phi_{\text {low }}\right) / 2$.

(b) A statistical estimate: one assumes that the full range of calculated fluxes represents a $\pm 3 \sigma$ interval. ${ }^{6}$ In this way one obtain a conventional $1 \sigma$ error $\Delta \Phi=\left(\Phi_{\text {high }}-\Phi_{\text {low }}\right) / 6$.

The relative uncertainties of the fluxes are reported in Table XI. They are the same (and fully correlated) for all elements, the 1- $\sigma$ error being about 15\%, at Kamioka and Gran Sasso. At Hawaii, where the mantle contribution is dominant, the error is much larger, as a consequence of the large uncertainties of the lower mantle's composition.

When using these errors, one has to remark that uncertainties associated with abundances in the crust and in the upper mantle are deduced from the spread of observational data, whereas the estimates for the lower mantle, which cannot be accessed by observations, completely rely on theoretical arguments. In addition, one should also take into account the detailed geological structure around the detector for more precise flux estimates.

\footnotetext{
${ }^{5}$ Clearly this model does not satisfy the BSE constraint on the total U, Th, and K masses in the Earth.

${ }^{6}$ If unhappy with this conventional assumption, the reader can rescale $\sigma$.
} 


\section{FROM FLUXES TO SIGNALS AND DETECTORS}

Geoneutrinos can be detected by means of inverse beta reactions

$$
\bar{\nu}_{e}+(Z, A) \rightarrow e^{+}+(Z-1, A)
$$

where the positron kinetic energy $T$ is related to the antineutrino energy $E$ by $T=E-E_{0}$, with $E_{0}=m_{Z-1}+m_{e}-m_{Z} \cdot{ }^{7}$ The differential event yield as a function of $T$ is given by

$$
\frac{d N}{d T}=N_{Z} t \sigma(E) \sum_{X} w_{X}(E) \int_{0}^{2 R_{\oplus}} d R f_{X}(R) P_{e e}(E, R)
$$

where $N_{Z} t$ is the exposure (number of target nuclei times the live time), $\sigma(E)$ is the cross section of reaction (7), $T=E-E_{0}$ and the integral is over the distance $R$ from the detector.

The survival probability of $\bar{\nu}_{e}$ produced at distance $R$ with energy $E$ is

$$
P_{e e}(E, R)=1-\sin ^{2}(2 \theta) \sin ^{2}\left(\frac{\delta m^{2} R}{4 E}\right) .
$$

For each element, the differential produced flux $f_{X}(R)$ is defined in Eq. (15), $w_{X}(E)$ is the energy spectrum of the $\bar{\nu}_{e}$ from the decay chain [26] of element $X$ and normalized to 1 ,

$\int_{0}^{\infty} d E w_{X}(E)=1$. For simplicity we neglect the finite energy resolution of the detector and assume $100 \%$ detection efficiency.

Another interesting observable is the total geoneutrino yield

$$
N=\int_{0}^{T_{\max }} d T \frac{d N}{d T}
$$

where $T_{\max }$ is the maximal positron energy.

The classical approach to low energy antineutrino detection is by using hydrogen compounds as target, by means of $\bar{\nu}_{e}+p \rightarrow e^{+}+n$. Since $E_{0}=m_{n}+m_{e}-m_{p}=1.804 \mathrm{MeV}$, this reaction is suitable for antineutrinos from uranium and thorium progenies $\left(E_{\max }=3.26\right.$ and $2.25 \mathrm{MeV}$, respectively), whereas antineutrinos from potassium $\left(E_{\max }=1.31 \mathrm{MeV}\right)$ are below threshold.

\footnotetext{
${ }^{7} \mathrm{~A}$ frequently used variable is the visible energy $E_{\mathrm{vis}}=T+2 m_{e}$ which is the energy released in the slowing down and subsequent annihilation of the positron.
} 


\section{A. Total yields}

We discuss first the total geoneutrino yield $N$, which is experimentally more accessible than the differential spectrum. In view of the structure of the survival probability, see Eq. (9), it can be written as

$$
N=N_{\text {no }}\left[1-\sin ^{2}(2 \theta) \chi\left(\delta m^{2}\right)\right],
$$

where $N_{\text {no }}$ is the yield for no oscillation.

The function $\chi$ depends on the uranium and thorium distributions inside Rarth and on the detector position. Obviously $\chi$ tends to $0(1 / 2)$ for small (large) values of $\delta m^{2}$. We have computed $\chi$ in the reference model for some sites of interest, see Fig. 3. At all locations and for $\delta m^{2}>4 \times 10^{-5} \mathrm{eV}^{2}$, the function $\chi$ differs from its asymptotic value by less than $2 \%$. Using the asymptotic value of the survival probability and the best fit value of the mixing angle [3], one finds

$$
N=N_{\text {no }}\left[1-0.5 \sin ^{2}(2 \theta)\right]=0.57 N_{\text {no }}
$$

In Fig. 4 we show the relative contributions of different distances to the total yield: for the most interesting values of $\delta m^{2}$ the region within $30 \mathrm{~km}$ from Kamioka contributes about $15 \%$ of the total. The no oscillation yield $N_{\text {no }}$ is determined in terms of the total produced fluxes from uranium and thorium [9]

$$
N_{\mathrm{no}}=13.2 \Phi_{\mathrm{U}}+4.0 \Phi_{\mathrm{Th}}
$$

for an exposure of $10^{32}$ proton yr with fluxes $\Phi$ in units of $10^{6} \mathrm{~cm}^{-2} \mathrm{~s}^{-1}$.

The no oscillation yields, calculated with the fluxes of the reference model, are shown in Table XII. In the same table we also present the estimated $1 \sigma$ errors, obtained by propagating those on the produced fluxes (which are dominant over the other uncertainties from cross sections, decay spectrum, etc.) and the minimal and maximal predictions.

For the Kamioka site the prediction of the reference model (normalized ${ }^{8}$ to $10^{32}$ proton yr and $100 \%$ efficiency) is $N_{\text {no }}=61$ in good agreement with the "best model" of Refs. [8, 10], $N_{\text {no }}=67 \mathrm{TNU}$, in between the values of Ref. [7], $N_{\text {no }}=43 \mathrm{TNU}$, and of model $1 \mathrm{~b}$ of

\footnotetext{
${ }^{8}$ It is useful to introduce a terrestrial neutrino unit (TNU) for event rates, defined as one event per $10^{32}$ target nuclei per year, or $3.17110^{-40} \mathrm{~s}^{-1}$ per target nucleus. This unit is analogous to the solar neutrino unit (SNU) [27].
} 
Ref. [6], $N_{\text {no }}=75$ TNU. An experimental value for $N_{\text {no }}=156$ TNU can be deduced from the nine geoevents reported by KamLAND, assuming $P_{e e}=0.57$. All the above predictions are consistent with the experimental result within its statistical error (about $60 \%[9]$ ).

The total yields predicted in our reference model for a number of locations are presented in Fig. 5. We remind the reader that geoneutrino fluxes are superimposed to the low-energy tail of antineutrinos from nuclear reactors, which can provide in this respect an important background, as first pointed out by Lagage 28]. This effect is clearly dependent on location and it has been extensively discussed in Ref. [10]. In particular, the event yield from reactors has been estimated as about 300 TNU (no oscillations) at Kamioka and about 70 TNU at Gran Sasso.

\section{B. Event spectra}

A more detailed information is contained in the event spectrum $d N / d T$ and a relevant question is whether the spectrum is deformed because of oscillations. From Eqs (8) and (9) the event distribution with energy can be written as

$$
\frac{d N}{d T}=\left(\frac{d N}{d T}\right)_{\text {no }}\left[1-\sin ^{2}(2 \theta) \psi\left(T, \delta m^{2}\right)\right]
$$

where $T$ is the positron kinetic energy.

The no-oscillation spectrum $d N_{\text {no }} / d T$ is shown in Fig. 6] for Kamikande. The function $\psi\left(T, \delta m^{2}\right)$ represents the modification to the event spectrum due to oscillations. It is plotted for Kamioka for a few values of $\delta m^{2}$ in Fig. [7. One sees that oscillations produce a moderate distortion for the two smallest values of $\delta m^{2}$ and the distortion is negligible for the largest values of $\delta m^{2}$.

\section{CONCLUDING REMARKS}

We summarize here the main points of this paper

(i) We have provided a reference model for the produced fluxes of geoneutrinos, estimating its uncertainties in view of available data and geochemical inferences about $\mathrm{U}$, Th, and $\mathrm{K}$ distribution in Earth's interior. When normalized to an exposure of $10^{32}$ proton yr, an averaged survival probability $\left\langle P_{e e}\right\rangle=0.57$ and a $100 \%$ detection efficiency, the predicted 
events for KamLAND are

$$
N(\mathrm{U})=28 \pm 4.7 \quad, \quad N(\mathrm{Th})=7 \pm 1.2
$$

Errors have been estimated so as correspond to $1 \sigma$ confidence level and are (almost) completely correlated:

$$
N(\mathrm{U}+\mathrm{Th})=35 \pm 6
$$

(ii) Concerning the estimated errors, we remark that uncertainties associated with abundances in the crust and in the upper mantle are deduced from the spread of observational data, whereas the estimates for the lower mantle, which cannot be accessed by observations, completely rely on theoretical arguments. In addition, one should also take into account the detailed geological structure around the detector for more precise flux estimates.

(iii) We have also investigated extreme models, corresponding the the minimal and maximal amounts of $\mathrm{U}$ and Th which could be present on Earth. At KamLAND we predict

$$
N^{\text {low }}(\mathrm{U}+\mathrm{Th})=29 \quad \text { and } \quad N^{\text {high }}(\mathrm{U}+\mathrm{Th})=74 \quad .
$$

In these two extreme models $\mathrm{U}$, Th, and $\mathrm{K}$, in the BSE proportions, produce a radiogenic heat $H_{\mathrm{rad}}=9$ and $40 \mathrm{TW}$, respectively. If experimental results come out close to the minimum, then uranium and thorium provide a minor contribution to Earth's energetics: either Earth's heat flow is mainly non radiogenic or a significant amount of potassium has to be hidden in Earth's interior. If values near to the maximal are found from experiments, then radiogenic contribution is the main supply of Earth's heat flow, and one can exclude models where significant amounts of potassium are hidden in Earth's core.

(iv) Predictions for detectors at several locations are also given, see Table XII and Fig. [5. We remark that a detector located far from the continental crust could provide significant information on the structure of the mantle, particularly when compared with data from

detectors at sites where (as in KamLAND and Borexino) the contribution of Earth's crust is important.

\section{Acknowledgments}

We are grateful for useful comments and discussions to B. Ricci, L. Beccaluva, T. Lasserre, E. Lisi, R. Marcolongo, G. Ottonello, S. Schönert, and R. Vannucci. This work was partially 
supported by MIUR (Ministero dell'Istruzione, dell'Università e della Ricerca) under PRIN 2001 and PRIN 2002.

[1] KamLAND Collaboration, K. Eguchi et al., Phys. Rev. Lett. 90, 021802 (2003) arXiv:hep-ex/0212021.

[2] SNO Collaboration, Q. R. Ahmad et al., Phys. Rev. Lett. 89, 011301 (2002) arXiv:nucl-ex/0204008.

[3] G. L. Fogli, E. Lisi, A. Marrone, D. Montanino, A. Palazzo, and A. M. Rotunno, Phys. Rev. D 67, 073002 (2003) arXiv:hep-ph/0212127.

[4] G. Eder, Nucl. Phys. 78, 657 (1966).

[5] L. M. Krauss, S. L. Glashow, and D. N. Schramm, Nature (London) 310, 191 (1984).

[6] R. S. Raghavan, S. Schönert, S. Enomoto, J. Shirai, F. Suekane, and A. Suzuki, Phys. Rev. Lett. 80, 635 (1998).

[7] C. G. Rothschild, M. C. Chen, and F. P. Calaprice, Geophy. Res. Lett. 25, 1083 (1998) arXiv:nucl-ex/9710001.

[8] G. Fiorentini, F. Mantovani, and B. Ricci, Phys. Lett. B 557, 139 (2003) arXiv:nucl-ex/0212008.

[9] G. Fiorentini, T. Lasserre, M. Lissia, B. Ricci, and S. Schönert, Phys. Lett. B 558, 15 (2003) arXiv:hep-ph/0301042.

[10] G. Fiorentini, M. Lissia, F. Mantovani, and B. Ricci, arXiv:physics/0305075.

[11] H. Nunokawa, W. J. Teves, and R. Z. Funchal, arXiv:hep-ph/0308175.

[12] Chemical Reservoirs and Convection in the Earth's Mantle. Papers of a Discussion Meeting held at The Royal Society on 16 and 17 January, 2002, edited by J. H. Davies, J. P. Brodholt and B. J. Wood (The Royal Society, London, 2002).

[13] V. Rama Murthy, Win Van Westrenen, and Yingwei Fei, Nature (London) 423, 163 (2003).

[14] C. Bassin, G. Laske. and G. Masters, EOS Trans. Am. Geophys. Union 81, F897 (2000) http://mahi.ucsd.edu/Gabi/rem.html.

[15] A. M. Dziewonski and D. L. Anderson, Phys. Earth Planet. Interact. 25, 297 (1981).

[16] S. R. Taylor and S. M. McLennan, The Continental Crust: its Composition and Evolution (Blackwell Scientic, Oxford, 1985). 
[17] K. H. Wedepohl, Geochim. Cosmochim. Acta 59, 1217 (1995).

[18] GERM, the Geochemical Earth Reference Model, is available on the web at http://earthref.org.

[19] K. P. Jochum et al., Nature (London) 322, 221 (1986).

[20] W. M. White, Earth Planet Sci. Lett. 115 , 211 (1993) arXiv:hep-ph/0212202.

[21] R. K. O’Nions, D. McKenzie, Philos. Trans. R. Soc. London A342, 65 (1993).

[22] A. W. Hofmann, Earth Planet Sci. Lett. 90, 297 (1988).

[23] R. E. Zartman and S. Haines, Geochim. Cosmochim. Acta 52, 1327 (1988).

[24] BOREXINO Collaboration, G. Alimonti et al., Astropart. Phys. 16, 205 (2002.

[25] D. M. Shaw, J. J. Cramer, M. D. Higgins, and M. G. Truscott, in The Nature of the Lower Continental Crust, edited by J. Dawson et al. (Geological Society of London, London, 1986), p. 275.

[26] H. Behrens and J. Janecke, Numerical Tables for Beta Decay and Electron Capture (SpringerVerlag, Berlin, 1969).

[27] J. N. Bahcall, Neutrino Astrophysics (Cambridge University Press., Cambridge, 1989), p. 3.

[28] P. O. Lagage, Nature (London) 316, 420 (1985).

[29] W. F. McDonough, S. S. Sun, A. E. Ringwood, E. Jagoutz, and A. W. Hofmann, Geochim. Cosmochim. Acta 56, 1001 (1992).

[30] H. Wänke, G. Dreibus, and E. Jagoutz, in Archean Geochemistry, edited by A. Kroener, G N. Hänson, and A. M. Goodwun (Springer-Verlag, New York, 1984), pp. 1-24.

[31] M. S. Quinby-Hunt and K. K. Turekian, EOS Trans. Am. Geophys. Union 64, 130 (1983).

[32] T. Plank and C. H. Langmuir, Chem. Geol. 145, 325 (1998).

[33] K. C. Condie, Chem. Geol. 104, 1 (1993).

[34] R. L. Rudnick and D. M. Fountain, Rev. Geophys. 33, 267 (1995). 
TABLE I: Abundances in the bulk silicate Earth model.

\begin{tabular}{llll}
\hline \hline$a(\mathrm{U})$ & $\mathrm{Th} / \mathrm{U}$ & $\mathrm{K} / \mathrm{U}$ & Remarks \\
\hline $2.1 \times 10^{-8}$ & 4.0 & $1.14 \times 10^{4}$ & {$[29]$} \\
$2.3 \times 10^{-8}$ & & & {$[30]$} \\
$2.0 \times 10^{-8}$ & 4.0 & $1.27 \times 10^{4}$ & {$[22]$} \\
$1.8 \times 10^{-8}$ & 3.6 & $1.0 \times 10^{4}$ & {$[16]$} \\
\hline $2.0 \times 10^{-8}$ & 3.9 & $1.14 \times 10^{4}$ & average \\
\hline \hline
\end{tabular}

TABLE II: Uranium abundances in Earth's interior.

\begin{tabular}{lccl}
\hline \hline Layer & $\begin{array}{c}\text { Available data } \\
\text { ( }\end{array}$ & $\begin{array}{c}\text { Adopted value Remarks } \\
a^{\text {ref }}(\mathrm{U})\end{array}$ & \\
\hline Oceans \& Seawater & $3.2 \times 10^{-9}$ & $3.2 \times 10^{-9}$ & {$[31]$} \\
Sediments & $1.68 \times 10^{-6}$ & $1.68 \times 10^{-6}$ & {$[32]$} \\
Upper CC & $(2.2 ; 2.4 ; 2.5 ; 2.8) \times 10^{-6}$ & $2.5 \times 10^{-6}$ & Average of [33], [33], [17], [16] \\
Middle CC & $1.6 \times 10^{-6}$ & $1.6 \times 10^{-6}$ & {$[34]$} \\
Lower CC & $(0.20 ; 0.28 ; 0.93 ; 1.1) \times 10^{-6}$ & $0.62 \times 10^{-6}$ & Average of [34], [16], [17], [25] \\
Oceanic crust & $0.1 \times 10^{-6}$ & $0.1 \times 10^{-6}$ & {$[16]$} \\
Upper mantle & $(5 ; 8) \times 10^{-9}$ & $6.5 \times 10^{-9}$ & Average of [19], [23] \\
Lower mantle & & $13.2 \times 10^{-9}$ & From Eq. (33) with \\
& & & $a_{\text {BSE }}(\mathrm{U})=2 \times 10^{-8}$ \\
Core & & 0 & \\
\hline \hline
\end{tabular}


TABLE III: Thorium abundances in Earth's interior.

\begin{tabular}{|c|c|c|c|c|}
\hline Layer & $\begin{array}{l}\text { Available data } \\
\text { Th/U }\end{array}$ & $\begin{array}{l}\text { Average } \\
\langle\mathrm{Th} / \mathrm{U}\rangle\end{array}$ & $\begin{array}{l}\text { Adopted value } \\
\qquad a^{\mathrm{ref}}(\mathrm{Th})\end{array}$ & Remarks \\
\hline Oceans \& Seawater & 0 & 0 & 0 & [31] \\
\hline Sediments & 4.11 & 4.11 & $6.9 \times 10^{-6}$ & 32 \\
\hline Upper CC & $3.8 ; 3.8 ; 3.9 ; 4.1$ & 3.9 & $9.8 \times 10^{-6}$ & Average of [34], [33], [33], [17] \\
\hline Middle CC & 3.8 & 3.8 & $6.1 \times 10^{-6}$ & [34] \\
\hline Lower CC & $3.8 ; 6.0 ; 7.0 ; 7.1$ & 6 & $3.7 \times 10^{-6}$ & Average of [16], [34], [25], [17] \\
\hline Oceanic crust & 2.2 & 2.2 & $0.22 \times 10^{-6}$ & [16] \\
\hline Upper mantle & $2.58 ; 2.63 ; 2.7 ; 2.73$ & 2.66 & $17.3 \times 10^{-9}$ & Average of [20], [21], [22], [23] \\
\hline Lower mantle & & & $52.0 \times 10^{-9}$ & $\begin{array}{l}\text { From Eq. (3) with } \\
a_{\mathrm{BSE}}(\mathrm{Th})=7.8 \times 10^{-8}\end{array}$ \\
\hline Core & & & 0 & \\
\hline
\end{tabular}

TABLE IV: Potassium abundances in Earth's interior.

\begin{tabular}{lcccl}
\hline \hline Layer & $\begin{array}{c}\text { Available data } \\
(\mathrm{K} / \mathrm{U}) \times 10^{-4}\end{array}$ & $\begin{array}{c}\text { Average } \\
\langle\mathrm{K} / \mathrm{U}\rangle \times 10^{-4}\end{array}$ & $\begin{array}{c}\text { Adopted value Remarks } \\
a^{\mathrm{ref}}(\mathrm{K})\end{array}$ \\
\hline Oceans \& Seawater & 12.5 & 12.5 & $4.0 \times 10^{-4}$ & {$[31]$} \\
Sediments & 1.0 & 1.0 & $1.7 \times 10^{-2}$ & {$[32]$} \\
Upper CC & $0.99 ; 1.0 ; 1.03 ; 1.10$ & 1.03 & $2.57 \times 10^{-2}$ & Average of [16], [17], [33], [33] \\
Middle CC & 1.04 & 1.04 & $1.67 \times 10^{-2}$ & {$[34]$} \\
Lower CC & $1 ; 1.2 ; 1.4$ & 1.2 & $0.72 \times 10^{-2}$ & Average of [16], [25], [17] \\
Oceanic crust & 1.25 & 1.25 & $0.125 \times 10^{-2}$ & [16] \\
Upper mantle & & & $0.78 \times 10^{-4}$ & From K/U approx. constancy \\
Lower mantle & & & $1.6 \times 10^{-4}$ & From Eq. (33) with \\
Core & & & $a_{\mathrm{BSE}}(\mathrm{K})=2.32 \times 10^{-4}$ \\
\hline \hline
\end{tabular}


TABLE V: Uranium: masses, radiogenic heat, and predicted fluxes. Units are $10^{17} \mathrm{~kg}$, TW and $10^{6} \mathrm{~cm}^{-2} \mathrm{~s}^{-1}$, respectively. The reference values, lower and upper limits are labeled as ref, low, and high, respectively. Crust summarizes CC and OC; UM (LM) denotes upper (lower) mantle.

\begin{tabular}{lcccccc}
\hline \hline & & Himalaya & Gran Sasso & Kamioka & Hawaii \\
& & & $33^{\circ} \mathrm{N} 85^{\circ} \mathrm{E}$ & $42^{\circ} \mathrm{N} 14^{\circ} \mathrm{E}$ & $36^{\circ} \mathrm{N} 137^{\circ} \mathrm{E}$ & $20^{\circ} \mathrm{N} 156^{\circ} \mathrm{W}$ \\
\hline Crust low & 0.206 & 1.960 & 3.337 & 1.913 & 1.594 & 0.218 \\
Crust ref & 0.353 & 3.354 & 5.710 & 3.273 & 2.727 & 0.373 \\
Crust high & 0.413 & 3.920 & 6.674 & 3.826 & 3.187 & 0.436 \\
\hline UM low & 0.048 & 0.455 & 0.146 & 0.146 & 0.146 & 0.146 \\
UM ref & 0.062 & 0.591 & 0.189 & 0.189 & 0.189 & 0.189 \\
UM high & 0.077 & 0.727 & 0.233 & 0.233 & 0.233 & 0.233 \\
\hline LM low & 0.147 & 1.399 & 0.288 & 0.288 & 0.288 & 0.288 \\
LM ref & 0.389 & 3.695 & 0.760 & 0.760 & 0.760 & 0.760 \\
LM high & 1.177 & 11.182 & 2.299 & 2.299 & 2.299 & 2.299 \\
\hline Total low & 0.401 & 3.814 & 3.770 & 2.346 & 2.027 & 0.651 \\
Total ref & 0.804 & 7.639 & 6.659 & 4.222 & 3.676 & 1.322 \\
Total high & 1.666 & 15.828 & 9.206 & 6.358 & 5.720 & 2.968 \\
\hline \hline
\end{tabular}


TABLE VI: Thorium: masses, radiogenic heat, and predicted fluxes. Units are $10^{17} \mathrm{~kg}$, TW and $10^{6} \mathrm{~cm}^{-2} \mathrm{~s}^{-1}$, respectively. The reference values, lower and upper limits are labeled as ref, low, and high, respectively. Crust summarizes CC and OC; UM (LM) denotes upper (lower) mantle.

\begin{tabular}{lcccccc}
\hline \hline & & Himalaya & Gran Sasso & Kamioka & Hawaii \\
& & & $33^{\circ} \mathrm{N} 85^{\circ} \mathrm{E}$ & $42^{\circ} \mathrm{N} 14^{\circ} \mathrm{E}$ & $36^{\circ} \mathrm{N} 137^{\circ} \mathrm{E}$ & $20^{\circ} \mathrm{N} 156^{\circ} \mathrm{W}$ \\
\hline Crust low & 0.838 & 2.263 & 2.972 & 1.714 & 1.420 & 0.180 \\
Crust ref & 1.450 & 3.915 & 5.141 & 2.964 & 2.456 & 0.311 \\
Crust high & 1.722 & 4.649 & 6.105 & 3.520 & 2.916 & 0.370 \\
\hline UM low & 0.124 & 0.336 & 0.083 & 0.083 & 0.083 & 0.083 \\
UM ref & 0.166 & 0.447 & 0.111 & 0.111 & 0.111 & 0.111 \\
UM high & 0.207 & 0.558 & 0.138 & 0.138 & 0.138 & 0.138 \\
\hline LM low & 0.383 & 1.034 & 0.165 & 0.165 & 0.165 & 0.165 \\
LM ref & 1.532 & 4.135 & 0.658 & 0.658 & 0.658 & 0.65 \\
LM high & 4.590 & 12.393 & 1.973 & 1.973 & 1.973 & 1.973 \\
\hline Total low & 1.346 & 3.633 & 3.220 & 1.961 & 1.668 & 0.428 \\
Total ref & 3.147 & 8.497 & 5.910 & 3.733 & 3.225 & 1.080 \\
Total high & 6.519 & 17.600 & 8.216 & 5.631 & 5.028 & 2.481 \\
\hline \hline
\end{tabular}


TABLE VII: Potassium: masses, radiogenic heat, and predicted fluxes. Units are $10^{21} \mathrm{~kg}, \mathrm{TW}$, and $10^{6} \mathrm{~cm}^{-2} \mathrm{~s}^{-1}$, respectively. The reference values, lower and upper limits are labelled as ref, low, and high, respectively. Crust summarizes CC and OC; UM (LM) denotes upper (lower) mantle.

\begin{tabular}{|c|c|c|c|c|c|c|}
\hline & & & $\begin{array}{c}\text { Himalaya } \\
33^{\circ} \mathrm{N} 85^{\circ} \mathrm{E}\end{array}$ & $\begin{array}{l}\text { Gran Sasso } \\
42^{\circ} \mathrm{N} 14^{\circ} \mathrm{E}\end{array}$ & $\begin{array}{c}\text { Kamioka } \\
36^{\circ} \mathrm{N} 137^{\circ} \mathrm{E}\end{array}$ & $\begin{array}{c}\text { Hawaii } \\
20^{\circ} \mathrm{N} 156^{\circ} \mathrm{W}\end{array}$ \\
\hline & $M(\mathrm{~K})$ & $H(\mathrm{~K})$ & \multicolumn{4}{|c|}{$\Phi_{\mathrm{K}}$} \\
\hline Crust low & 0.210 & 0.757 & 12.429 & 7.126 & 5.941 & 0.851 \\
\hline Crust ref & 0.367 & 1.321 & 21.684 & 12.432 & 10.366 & 1.485 \\
\hline Crust high & 0.441 & 1.587 & 26.048 & 14.934 & 12.451 & 1.784 \\
\hline UM low & 0.057 & 0.207 & 0.634 & 0.634 & 0.634 & 0.634 \\
\hline UM ref & 0.075 & 0.269 & 0.824 & 0.824 & 0.824 & 0.824 \\
\hline UM high & 0.092 & 0.331 & 1.015 & 1.015 & 1.015 & 1.015 \\
\hline LM low & 0.177 & 0.636 & 1.254 & 1.254 & 1.254 & 1.25 \\
\hline LM ref & 0.471 & 1.697 & 3.343 & 3.343 & 3.343 & 3.34 \\
\hline LM high & 1.344 & 4.838 & 9.534 & 9.534 & 9.534 & 9.534 \\
\hline Total low & 0.444 & 1.600 & 14.317 & 9.014 & 7.829 & 2.739 \\
\hline Total ref & 0.913 & 3.287 & 25.852 & 16.600 & 14.533 & 5.652 \\
\hline Total high & 1.877 & 6.756 & 36.596 & 25.482 & 23.000 & 12.332 \\
\hline
\end{tabular}


TABLE VIII: Differential produced fluxes: the contributions from the crust at Kamioka. The distance $R$ is in $\mathrm{km}, f_{X}$ in $\mathrm{cm}^{-3} \mathrm{~s}^{-1}$.

\begin{tabular}{|c|c|c|c|}
\hline$R$ & $f_{\mathrm{U}}$ & $f_{\mathrm{Th}}$ & $f_{\mathrm{K}}$ \\
\hline 10 & $1.86 \mathrm{E}-01$ & $1.61 \mathrm{E}-01$ & $6.94 \mathrm{E}-01$ \\
\hline 20 & $2.29 \mathrm{E}-01$ & $1.97 \mathrm{E}-01$ & $8.55 \mathrm{E}-01$ \\
\hline 30 & $2.01 \mathrm{E}-01$ & $1.75 \mathrm{E}-01$ & $7.57 \mathrm{E}-01$ \\
\hline 40 & $1.59 \mathrm{E}-01$ & $1.45 \mathrm{E}-01$ & $6.07 \mathrm{E}-01$ \\
\hline 50 & $1.23 \mathrm{E}-01$ & $1.12 \mathrm{E}-01$ & $4.68 \mathrm{E}-01$ \\
\hline 60 & $9.86 \mathrm{E}-02$ & $9.04 \mathrm{E}-02$ & $3.76 \mathrm{E}-01$ \\
\hline 70 & 8.34E-02 & 7.65E-02 & $3.18 \mathrm{E}-01$ \\
\hline 80 & $7.51 \mathrm{E}-02$ & $6.87 \mathrm{E}-02$ & $2.86 \mathrm{E}-01$ \\
\hline 90 & $6.62 \mathrm{E}-02$ & $6.06 \mathrm{E}-02$ & $2.52 \mathrm{E}-01$ \\
\hline 100 & $5.57 \mathrm{E}-02$ & $5.11 \mathrm{E}-02$ & $2.12 \mathrm{E}-01$ \\
\hline 200 & $2.31 \mathrm{E}-02$ & $2.12 \mathrm{E}-02$ & $8.82 \mathrm{E}-02$ \\
\hline 300 & $8.15 \mathrm{E}-03$ & 7.39E-03 & $3.12 \mathrm{E}-02$ \\
\hline 400 & $5.24 \mathrm{E}-03$ & $4.74 \mathrm{E}-03$ & $2.01 \mathrm{E}-02$ \\
\hline 500 & $3.68 \mathrm{E}-03$ & $3.31 \mathrm{E}-03$ & $1.41 \mathrm{E}-02$ \\
\hline 600 & $2.61 \mathrm{E}-03$ & $2.35 \mathrm{E}-03$ & $1.00 \mathrm{E}-02$ \\
\hline 700 & $2.47 \mathrm{E}-03$ & $2.23 \mathrm{E}-03$ & $9.50 \mathrm{E}-03$ \\
\hline 800 & $2.53 \mathrm{E}-03$ & $2.29 \mathrm{E}-03$ & $9.68 \mathrm{E}-03$ \\
\hline 900 & $2.94 \mathrm{E}-03$ & $2.67 \mathrm{E}-03$ & $1.13 \mathrm{E}-02$ \\
\hline 1000 & $2.88 \mathrm{E}-03$ & $2.61 \mathrm{E}-03$ & $1.10 \mathrm{E}-02$ \\
\hline 2000 & $1.32 \mathrm{E}-03$ & $1.20 \mathrm{E}-03$ & $5.06 \mathrm{E}-03$ \\
\hline 3000 & $1.08 \mathrm{E}-03$ & $9.72 \mathrm{E}-04$ & $4.11 \mathrm{E}-03$ \\
\hline 4000 & $1.05 \mathrm{E}-03$ & $9.51 \mathrm{E}-04$ & $4.01 \mathrm{E}-03$ \\
\hline 5000 & $7.44 \mathrm{E}-04$ & $6.75 \mathrm{E}-04$ & $2.84 \mathrm{E}-03$ \\
\hline 6000 & $4.88 \mathrm{E}-04$ & $4.40 \mathrm{E}-04$ & $1.86 \mathrm{E}-03$ \\
\hline 7000 & $4.28 \mathrm{E}-04$ & $3.86 \mathrm{E}-04$ & $1.64 \mathrm{E}-03$ \\
\hline 8000 & $2.99 \mathrm{E}-04$ & $2.69 \mathrm{E}-04$ & $1.14 \mathrm{E}-03$ \\
\hline 9000 & $2.53 \mathrm{E}-04$ & $2.27 \mathrm{E}-04$ & $9.67 \mathrm{E}-04$ \\
\hline 10000 & $2.19 \mathrm{E}-04$ & $1.98 \mathrm{E}-04$ & $8.41 \mathrm{E}-04$ \\
\hline 11000 & $2.16 \mathrm{E}-04$ & $1.96 \mathrm{E}-04$ & $8.28 \mathrm{E}-04$ \\
\hline 12000 & $1.40 \mathrm{E}-04$ & $1.24 \mathrm{E}-04$ & $5.35 \mathrm{E}-04$ \\
\hline
\end{tabular}


TABLE IX: Differential produced fluxes: the contributions from the crust at Gran Sasso. The distance $R$ is in $\mathrm{km}, f_{X}$ in $\mathrm{cm}^{-3} \mathrm{~s}^{-1}$.

\begin{tabular}{|c|c|c|c|}
\hline$R$ & $f_{\mathrm{U}}$ & $f_{\mathrm{Th}}$ & $f_{\mathrm{K}}$ \\
\hline 10 & $1.48 \mathrm{E}-01$ & $1.29 \mathrm{E}-01$ & $5.48 \mathrm{E}-01$ \\
\hline 20 & $2.11 \mathrm{E}-01$ & $1.82 \mathrm{E}-01$ & $7.86 \mathrm{E}-01$ \\
\hline 30 & $1.80 \mathrm{E}-01$ & $1.59 \mathrm{E}-01$ & $6.79 \mathrm{E}-01$ \\
\hline 40 & $1.40 \mathrm{E}-01$ & $1.28 \mathrm{E}-01$ & $5.34 \mathrm{E}-01$ \\
\hline 50 & $1.12 \mathrm{E}-01$ & $1.03 \mathrm{E}-01$ & $4.26 \mathrm{E}-01$ \\
\hline 60 & $8.94 \mathrm{E}-02$ & $8.21 \mathrm{E}-02$ & $3.41 \mathrm{E}-01$ \\
\hline 70 & $7.66 \mathrm{E}-02$ & 7.04E-02 & $2.92 \mathrm{E}-01$ \\
\hline 80 & $6.59 \mathrm{E}-02$ & $6.05 \mathrm{E}-02$ & $2.51 \mathrm{E}-01$ \\
\hline 90 & $5.92 \mathrm{E}-02$ & $5.43 \mathrm{E}-02$ & $2.25 \mathrm{E}-01$ \\
\hline 100 & $5.22 \mathrm{E}-02$ & 4.79E-02 & $1.99 \mathrm{E}-01$ \\
\hline 200 & $2.30 \mathrm{E}-02$ & $2.11 \mathrm{E}-02$ & $8.75 \mathrm{E}-02$ \\
\hline 300 & $1.31 \mathrm{E}-02$ & $1.20 \mathrm{E}-02$ & $5.02 \mathrm{E}-02$ \\
\hline 400 & $1.14 \mathrm{E}-02$ & $1.04 \mathrm{E}-02$ & $4.34 \mathrm{E}-02$ \\
\hline 500 & $9.83 \mathrm{E}-03$ & $8.95 \mathrm{E}-03$ & $3.74 \mathrm{E}-02$ \\
\hline 600 & $7.52 \mathrm{E}-03$ & $6.81 \mathrm{E}-03$ & $2.86 \mathrm{E}-02$ \\
\hline 700 & $5.98 \mathrm{E}-03$ & $5.43 \mathrm{E}-03$ & $2.27 \mathrm{E}-02$ \\
\hline 800 & $5.01 \mathrm{E}-03$ & $4.56 \mathrm{E}-03$ & $1.91 \mathrm{E}-02$ \\
\hline 900 & $4.95 \mathrm{E}-03$ & $4.52 \mathrm{E}-03$ & $1.88 \mathrm{E}-02$ \\
\hline 1000 & $5.12 \mathrm{E}-03$ & $4.68 \mathrm{E}-03$ & $1.95 \mathrm{E}-02$ \\
\hline 2000 & $2.98 \mathrm{E}-03$ & $2.71 \mathrm{E}-03$ & $1.13 \mathrm{E}-02$ \\
\hline 3000 & $1.60 \mathrm{E}-03$ & $1.45 \mathrm{E}-03$ & $6.08 \mathrm{E}-03$ \\
\hline 4000 & $1.22 \mathrm{E}-03$ & $1.11 \mathrm{E}-03$ & $4.66 \mathrm{E}-03$ \\
\hline 5000 & 7.65E-04 & $6.91 \mathrm{E}-04$ & $2.91 \mathrm{E}-03$ \\
\hline 6000 & $5.98 \mathrm{E}-04$ & $5.42 \mathrm{E}-04$ & $2.28 \mathrm{E}-03$ \\
\hline 7000 & $5.66 \mathrm{E}-04$ & $5.14 \mathrm{E}-04$ & $2.16 \mathrm{E}-03$ \\
\hline 8000 & $4.44 \mathrm{E}-04$ & $4.02 \mathrm{E}-04$ & $1.69 \mathrm{E}-03$ \\
\hline 9000 & $2.20 \mathrm{E}-04$ & $1.97 \mathrm{E}-04$ & $8.41 \mathrm{E}-04$ \\
\hline 10000 & $8.20 \mathrm{E}-05$ & $7.18 \mathrm{E}-05$ & $3.19 \mathrm{E}-04$ \\
\hline 11000 & $1.61 \mathrm{E}-04$ & $1.46 \mathrm{E}-04$ & $6.20 \mathrm{E}-04$ \\
\hline 12000 & $1.27 \mathrm{E}-04$ & $1.14 \mathrm{E}-04$ & $4.88 \mathrm{E}-04$ \\
\hline
\end{tabular}


TABLE X: Differential produced fluxes: the contributions from the mantle. The distance $R$ is in $\mathrm{km}, f_{X}$ in $\mathrm{cm}^{-3} \mathrm{~s}^{-1}$.

\begin{tabular}{|c|c|c|c|}
\hline$R$ & $f_{\mathrm{U}}$ & $f_{\mathrm{Th}}$ & $f_{\mathrm{K}}$ \\
\hline 10 & $0.00 \mathrm{E}+00$ & $0.00 \mathrm{E}+00$ & $0.00 \mathrm{E}+00$ \\
\hline 20 & $0.00 \mathrm{E}+00$ & $0.00 \mathrm{E}+00$ & $0.00 \mathrm{E}+00$ \\
\hline 30 & $0.00 \mathrm{E}+00$ & $0.00 \mathrm{E}+00$ & $0.00 \mathrm{E}+00$ \\
\hline 40 & $0.00 \mathrm{E}+00$ & $0.00 \mathrm{E}+00$ & $0.00 \mathrm{E}+00$ \\
\hline 50 & $1.62 \mathrm{E}-04$ & $9.48 \mathrm{E}-05$ & 7.05E-04 \\
\hline 60 & $2.91 \mathrm{E}-04$ & $1.70 \mathrm{E}-04$ & $1.27 \mathrm{E}-03$ \\
\hline 70 & $3.77 \mathrm{E}-04$ & $2.21 \mathrm{E}-04$ & $1.64 \mathrm{E}-03$ \\
\hline 80 & 4.38E-04 & $2.57 \mathrm{E}-04$ & $1.91 \mathrm{E}-03$ \\
\hline 90 & $4.84 \mathrm{E}-04$ & $2.83 \mathrm{E}-04$ & $2.11 \mathrm{E}-03$ \\
\hline 100 & $5.19 \mathrm{E}-04$ & $3.04 \mathrm{E}-04$ & $2.26 \mathrm{E}-03$ \\
\hline 200 & $6.64 \mathrm{E}-04$ & $3.89 \mathrm{E}-04$ & $2.89 \mathrm{E}-03$ \\
\hline 300 & $7.08 \mathrm{E}-04$ & $4.14 \mathrm{E}-04$ & $3.08 \mathrm{E}-03$ \\
\hline 400 & 7.31E-04 & $4.28 \mathrm{E}-04$ & 3.19E-03 \\
\hline 500 & $7.53 \mathrm{E}-04$ & $4.41 \mathrm{E}-04$ & $3.28 \mathrm{E}-03$ \\
\hline 600 & $7.71 \mathrm{E}-04$ & $4.51 \mathrm{E}-04$ & $3.36 \mathrm{E}-03$ \\
\hline 700 & 8.49E-04 & $5.32 \mathrm{E}-04$ & $3.70 \mathrm{E}-03$ \\
\hline 800 & $9.83 \mathrm{E}-04$ & $6.74 \mathrm{E}-04$ & 4.30E-03 \\
\hline 900 & $1.09 \mathrm{E}-03$ & 7.83E-04 & $4.75 \mathrm{E}-03$ \\
\hline 1000 & 1.17E-03 & $8.70 \mathrm{E}-04$ & $5.12 \mathrm{E}-03$ \\
\hline 2000 & $1.49 \mathrm{E}-03$ & $1.22 \mathrm{E}-03$ & $6.56 \mathrm{E}-03$ \\
\hline 3000 & $1.48 \mathrm{E}-03$ & $1.24 \mathrm{E}-03$ & $6.51 \mathrm{E}-03$ \\
\hline 4000 & $1.11 \mathrm{E}-03$ & $9.27 \mathrm{E}-04$ & $4.88 \mathrm{E}-03$ \\
\hline 5000 & 8.88E-04 & $7.41 \mathrm{E}-04$ & $3.90 \mathrm{E}-03$ \\
\hline 6000 & $7.40 \mathrm{E}-04$ & $6.17 \mathrm{E}-04$ & $3.25 \mathrm{E}-03$ \\
\hline 7000 & $6.34 \mathrm{E}-04$ & $5.29 \mathrm{E}-04$ & $2.79 \mathrm{E}-03$ \\
\hline 8000 & $5.54 \mathrm{E}-04$ & 4.63E-04 & $2.44 \mathrm{E}-03$ \\
\hline 9000 & 4.93E-04 & $4.11 \mathrm{E}-04$ & $2.17 \mathrm{E}-03$ \\
\hline 10000 & $4.24 \mathrm{E}-04$ & $3.53 \mathrm{E}-04$ & $1.86 \mathrm{E}-03$ \\
\hline 11000 & $2.35 \mathrm{E}-04$ & $1.91 \mathrm{E}-04$ & $1.03 \mathrm{E}-03$ \\
\hline 12000 & $6.10 \mathrm{E}-05$ & $4.11 \mathrm{E}-05$ & $2.66 \mathrm{E}-04$ \\
\hline
\end{tabular}

TABLE XI: Fractional uncertainties of the produced fluxes.

\begin{tabular}{lcccc}
\hline \hline$\Delta \Phi / \Phi(\%)$ & Himalaya & Gran Sasso & Kamioka & Hawaii \\
\hline conventional $1 \sigma$ & 14 & 16 & 17 & 29 \\
\hline \hline
\end{tabular}


TABLE XII: Total yields. $N_{\text {no }}$ is the total number of geoevents $(\mathrm{U}+\mathrm{Th})$ in the absence of oscillations predicted from the reference model for $10^{32}$ proton yr (or in TNU) and $\Delta N_{\text {no }}$ is the " $1 \sigma$ " error. $N_{\text {no }}^{\text {low }}\left(N_{\text {no }}^{\text {high }}\right)$ is the minimal (maximal) prediction. For $\delta m^{2}>4 \times 10^{-5} \mathrm{eV}^{2}$ the geoevent yield is $N=N_{\text {no }}\left[1-0.5 \sin ^{2}(2 \theta)\right]$.

\begin{tabular}{lrrrr}
\hline \hline Location & $N_{\text {no }}$ & $\Delta N_{\text {no }}$ & $N_{\text {no }}^{\text {low }}$ & $N_{\text {no }}^{\text {high }}$ \\
\hline Baksan & 91 & 13 & 51 & 131 \\
Hawaii & 22 & 6 & 10 & 49 \\
Himalaya & 112 & 15 & 63 & 154 \\
Homestake & 91 & 13 & 51 & 130 \\
Kamioka & 61 & 10 & 33 & 96 \\
La Palma & 37 & 8 & 19 & 67 \\
LGS & 71 & 11 & 39 & 106 \\
Pyhasalmi & 92 & 13 & 51 & 131 \\
Sudbury & 87 & 13 & 48 & 125 \\
Yucca Mountain & 70 & 11 & 38 & 106 \\
\hline \hline
\end{tabular}




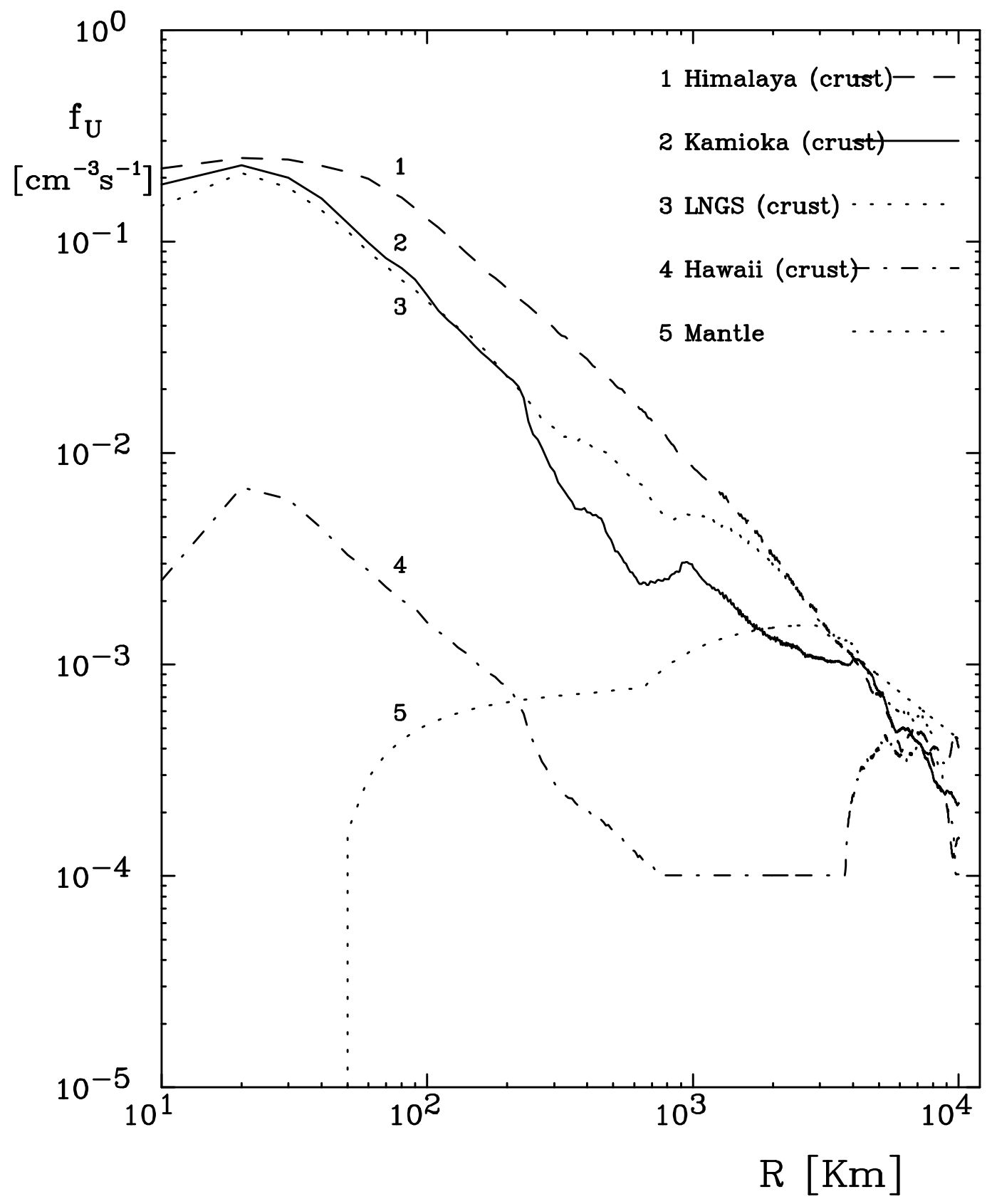

FIG. 1: Differential produced flux from uranium as a function of the distance $R$ from the detector. 


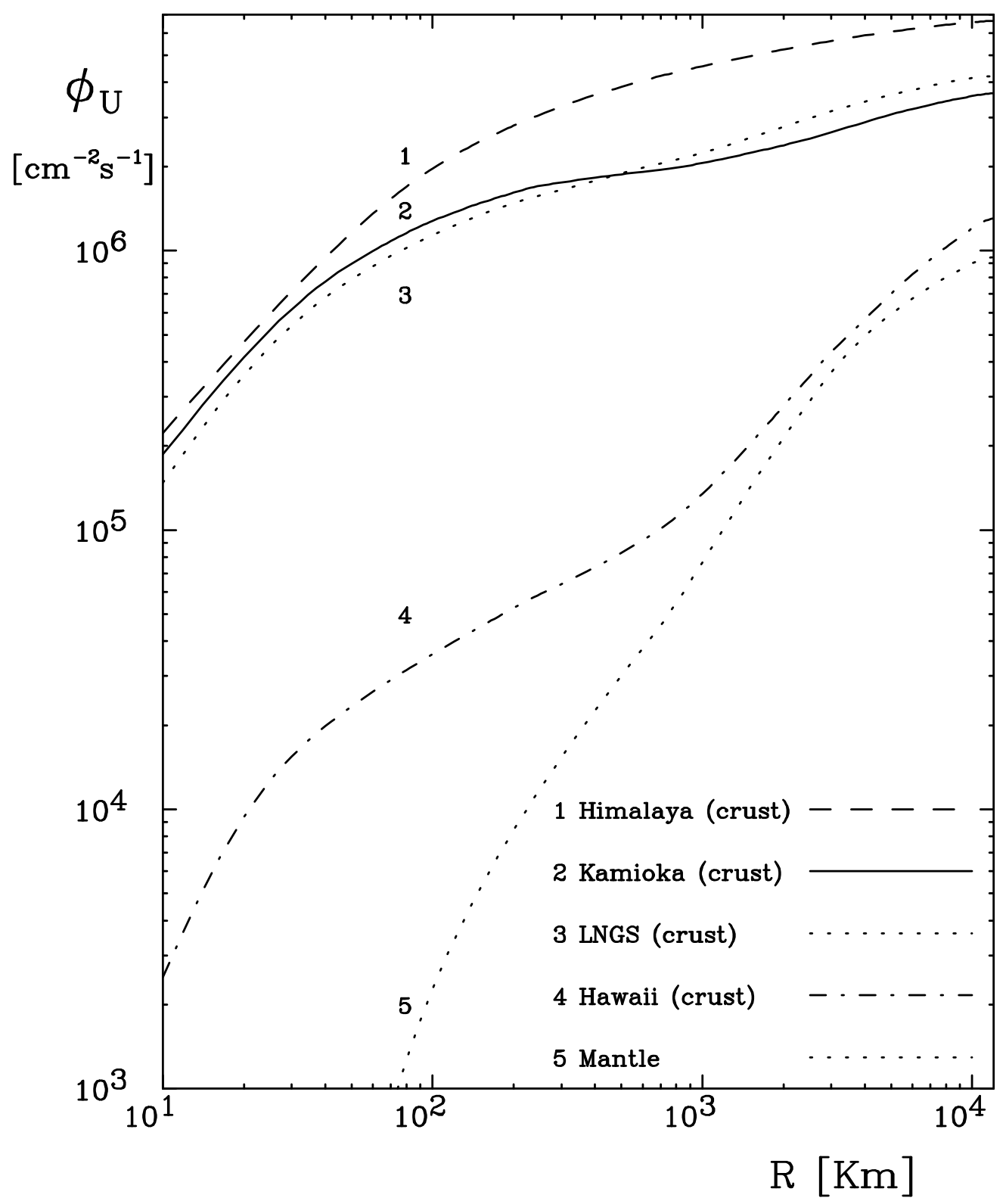

FIG. 2: Cumulated produced flux from uranium as a function of the distance $R$ from the detector. 


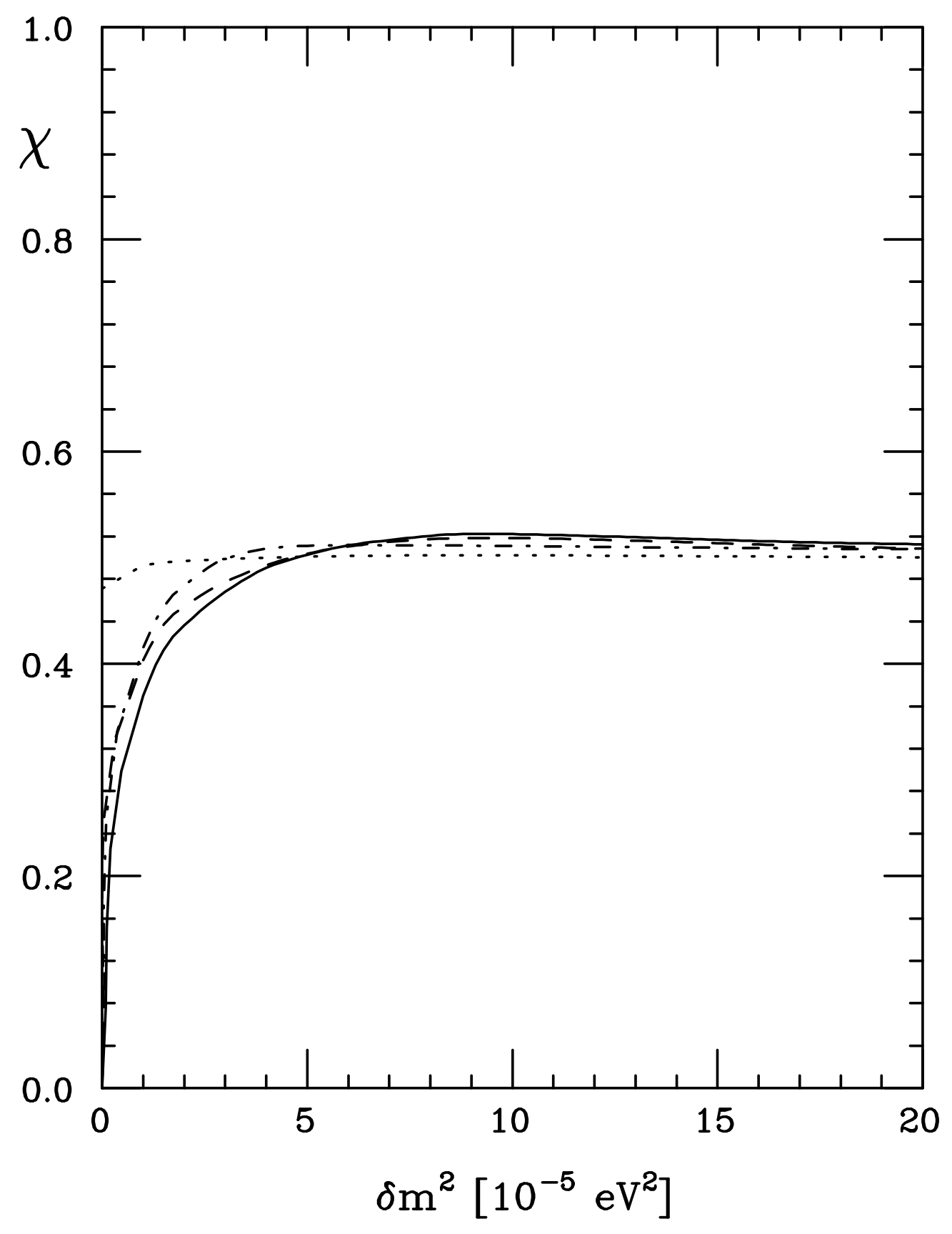

FIG. 3: Dependence of the yield on on $\delta m^{2}$. The figure shows the function $\chi=\left(N_{\text {no }}-\right.$ $N) /\left[\left(N_{\text {no }} \sin ^{2}(2 \theta)\right)\right]$, see Eq. (11), for four locations with $\delta m^{2}$ in units of $10^{-5} \mathrm{eV}^{2}$. Solid (dashed, dotted, dot-dashed) line applies to Kamioka (LNGS, Hawaii, Himalaya). 


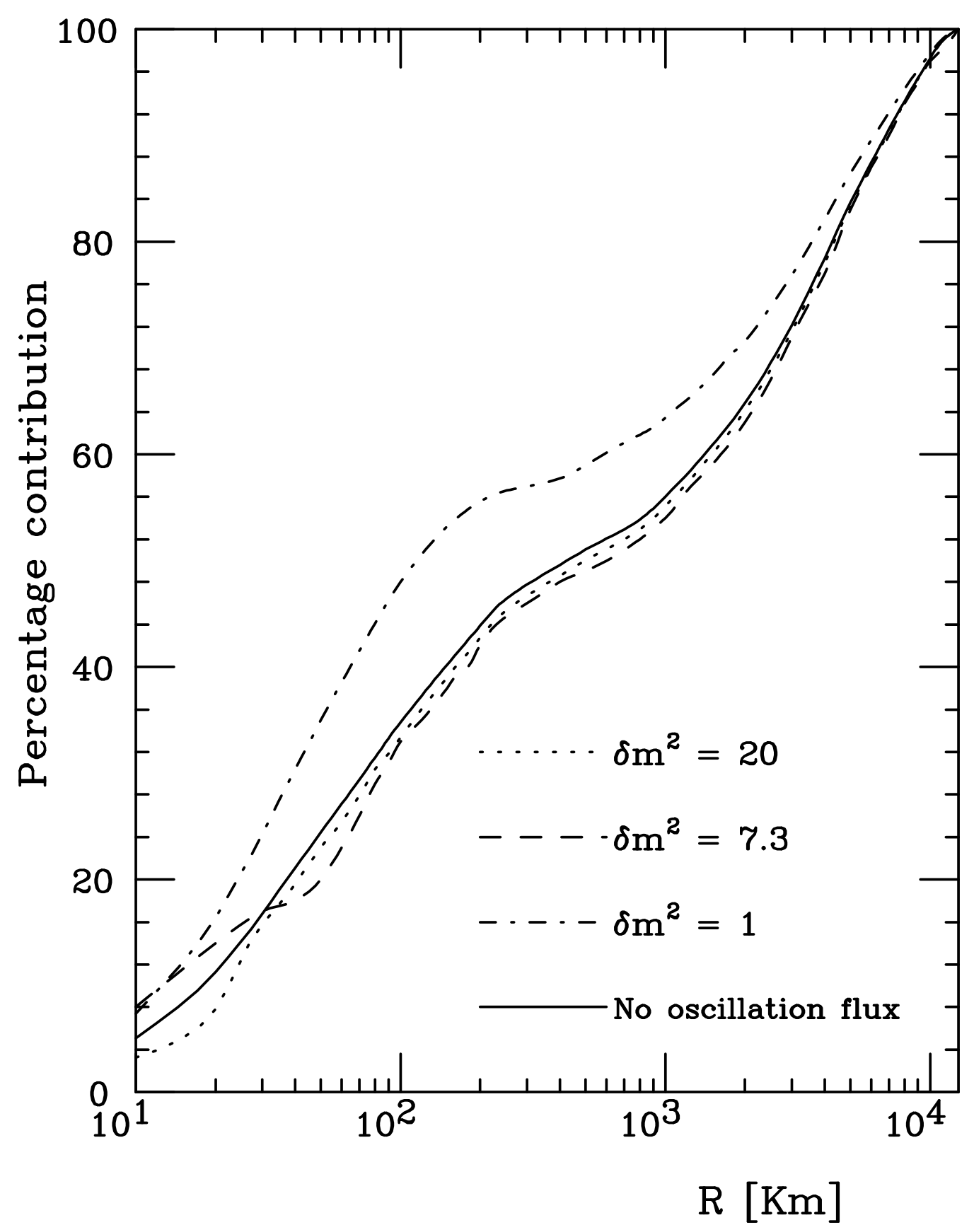

FIG. 4: Contributed signal as a function of distance. The percentage contribution to the event yield at Kamioka originating from sources within $R$ is shown for the indicated values of $\delta m^{2}$ in units of $10^{-5} \mathrm{eV}^{2}$ at fixed $\sin ^{2}(2 \theta)=0.863$. The percentage contributed neutrino flux without oscillation is also shown for comparison. 


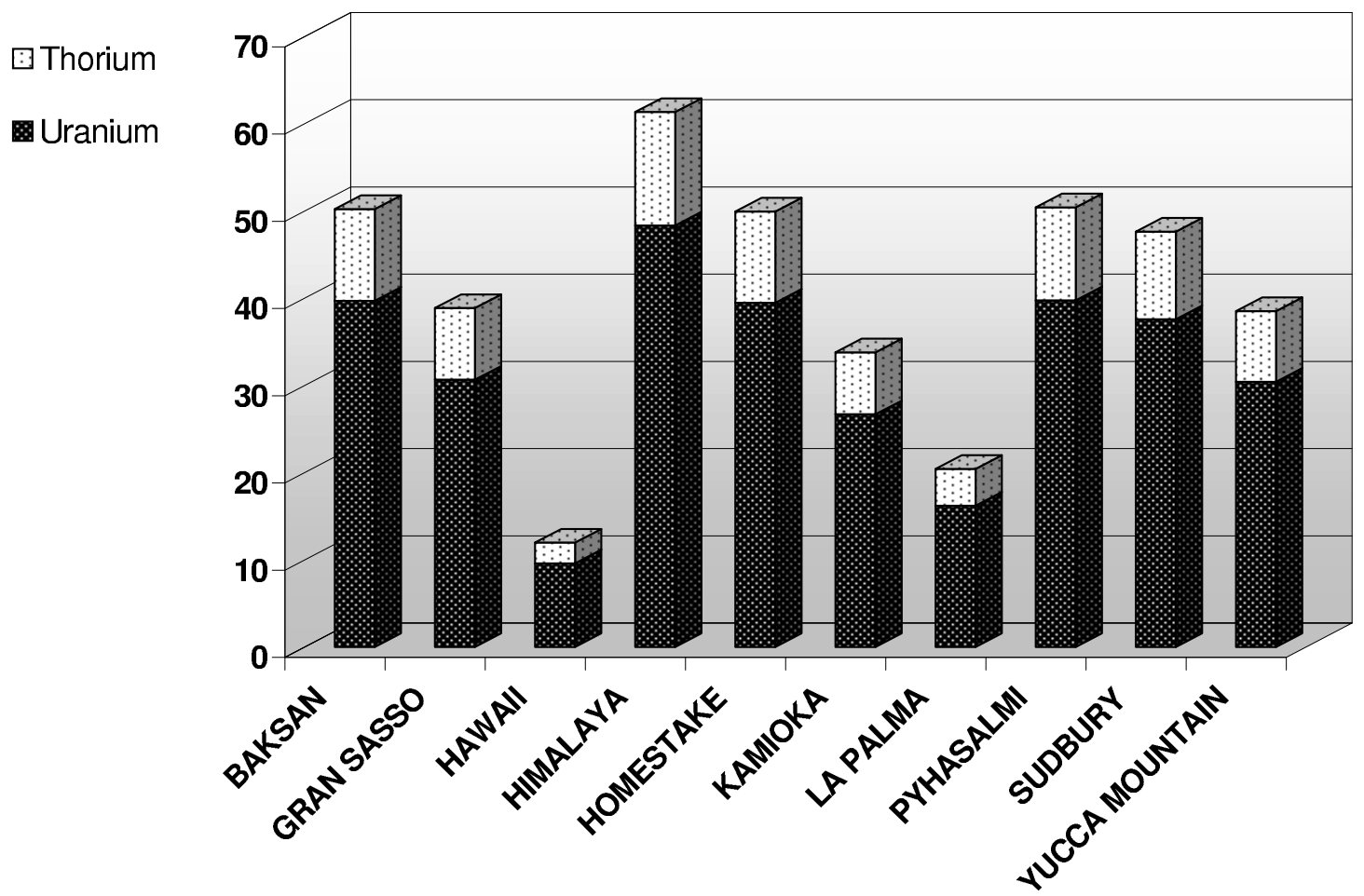

FIG. 5: Yields predicted in the reference model for $10^{32}$ proton yr, $100 \%$ efficiency, assuming the best fit oscillation parameters, $\delta m^{2}=7.3 \times 10^{-5} \mathrm{eV}^{2}$ and $\sin ^{2}(2 \theta)=0.863$. 


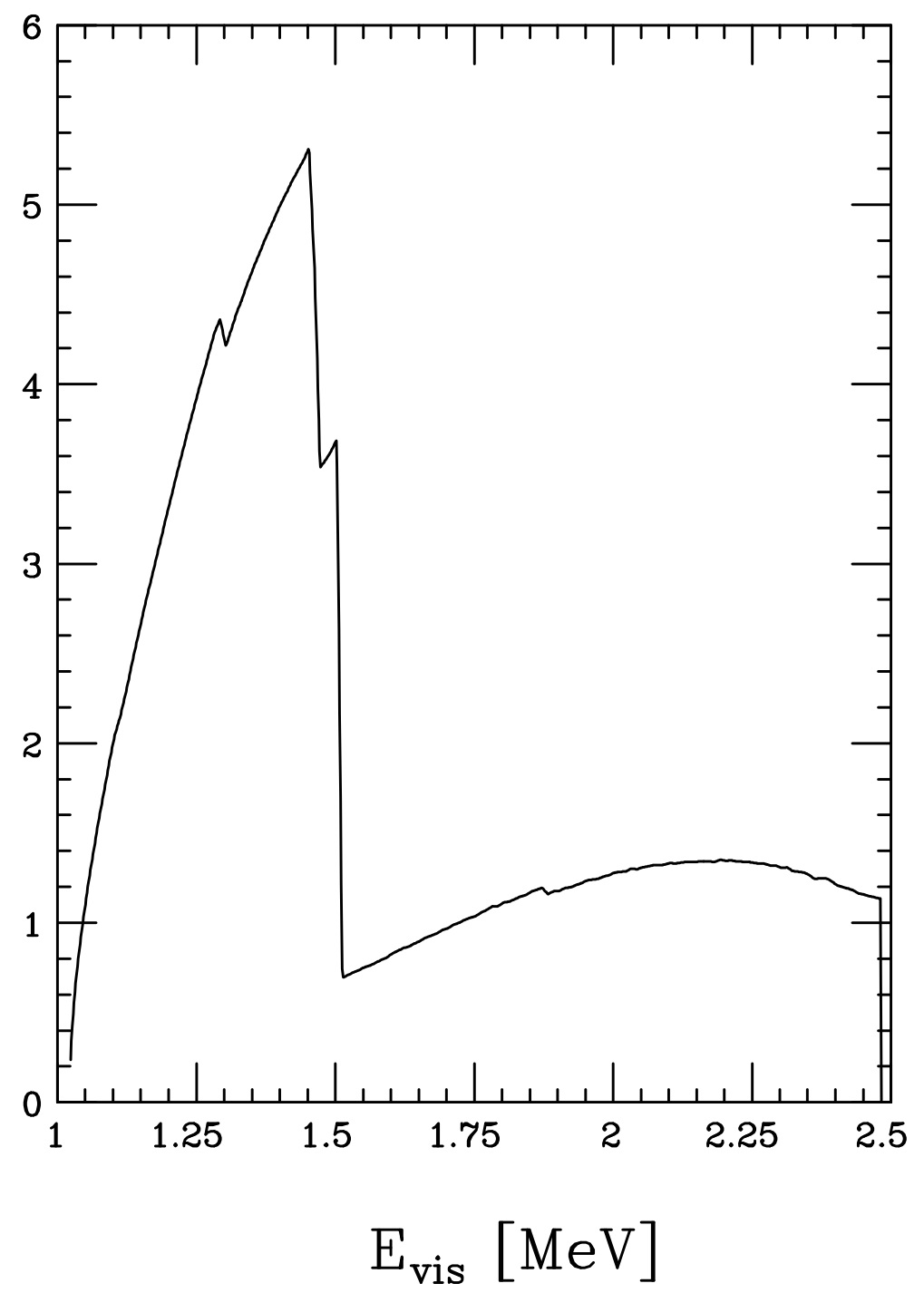

FIG. 6: Event spectrum as function of the visible energy $E_{\mathrm{vis}}=T+2 m_{e}$ in $\mathrm{MeV}$. The spectrum is calculated for the U/Th flux ratio expected at Kamioka with no oscillation and the normalization is arbitrary. 


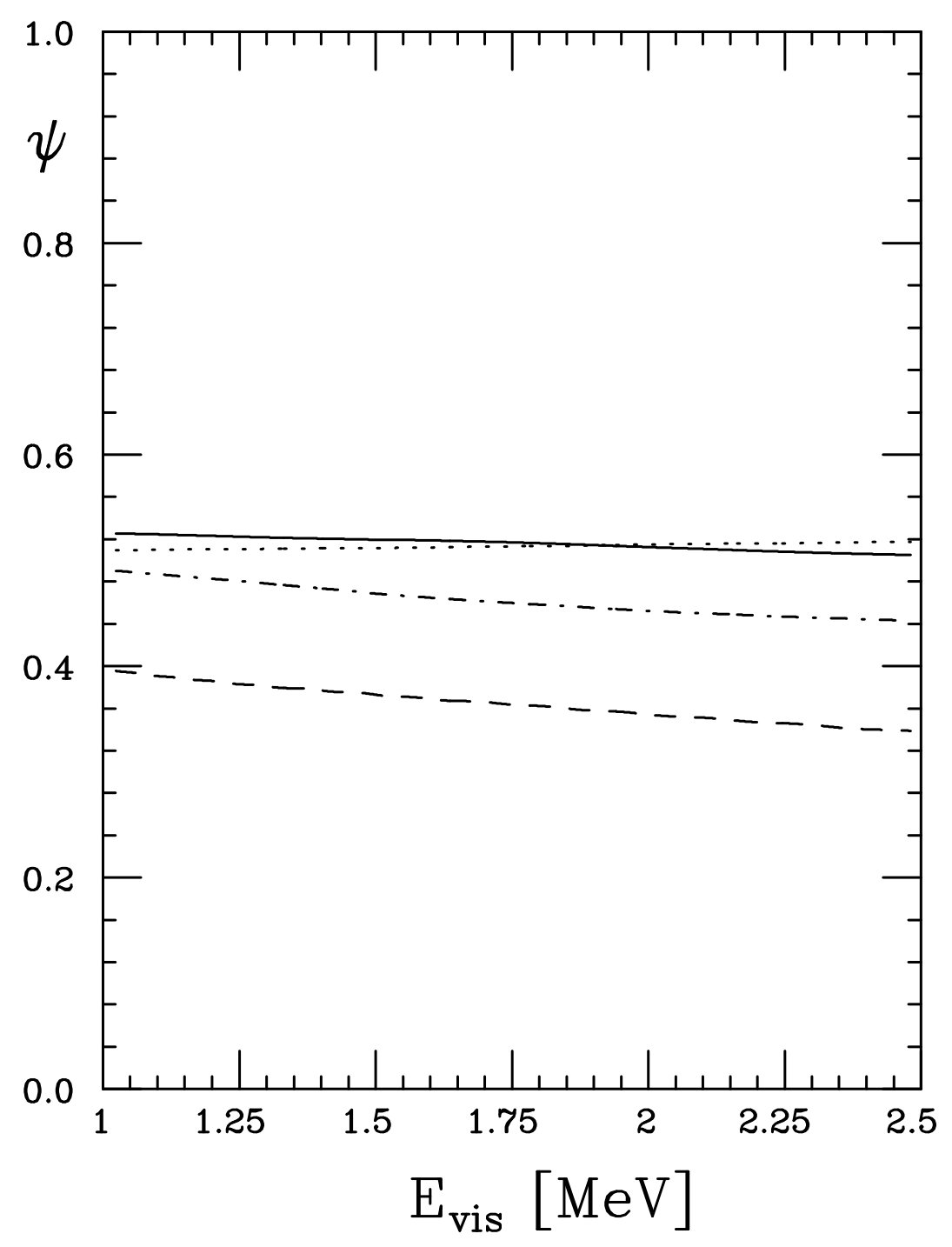

FIG. 7: Spectrum deformation. The function $\psi$, defined in Eq. (14), as function of the visible energy $E_{\mathrm{vis}}=T+2 m_{e}$ in $\mathrm{MeV}$ for four values of $\delta m^{2}: 1 \times 10^{-5} \mathrm{eV}^{2}$ (dash line), $3 \times 10^{-5} \mathrm{eV}^{2}$ (dot-dash line), $7.3 \times 10^{-5} \mathrm{eV}^{2}$ (solid line), and $20 \times 10^{-5} \mathrm{eV}^{2}$ (dot line). 